\title{
UNDERSTANDING CONSTRUCTION COMPETITIVENESS: THE CONTRIBUTION OF SYSTEM DYNAMICS
}

\section{DANGERFIELD, BRIAN. C., GREEN, STUART. D. AND AUSTIN, SIMON.A.}

\section{$\underline{\text { Purpose }}$}

Construction sector competitiveness has been a subject of interest for many years. Research too often focuses on the means of overcoming the 'barriers to change' as if such barriers were static entities. There has been little attempt to understand the dynamic interrelationship between the differing factors which impinge upon construction sector competitiveness. The paper outlines the benefits of taking a systems approach to construction competitiveness research.

\section{Design/methodology/approach}

The System Dynamics (SD) modelling methodology is described. This can provide practitioners with 'microworlds' within which they can explore the dynamic effects of different policy decisions. The data underpinning the use of SD was provided by interviews and case study research which allowed an understanding of the context within which practitioners operate.

\section{Findings}

The over-riding conclusion is that the system dynamics methodology has been shown to be capable of providing a means to assess the forces which shape the sustained competitiveness of construction firms. As such, it takes the assessment of strategic policy analysis in the construction sector onto a higher plane. The need to collect data and make retrospective assessments of competitiveness and strategic performance at the statistical level is not now the only modus operandi available

\section{Originality/value}


Novel research methodology which points towards an alternative research agenda for construction competitiveness research.

Keywords: Competitiveness; System Dynamics, Research, Industry Improvement, Policy Modelling

\section{Type $=$ Research paper}

\section{Introduction}

The paper has arisen from a three-year research project funded by the UK Engineering and Physical Sciences Research Council (EPSRC) aimed at improving the competitiveness of the UK construction industry. The research was funded on the basis of competitive peer review and was predicated on the observation that the post-Egan (date?) industry improvement agenda was becoming increasingly disconnected from the day-today challenges faced by firms in the construction sector. The aim was to bring a fresh perspective to the construction competitiveness research agenda by better understanding how competiveness is enacted within the sector, and how construction firms might better respond to opportunities in the future.. The research comprised a unique collaboration between the universities of Reading, Loughborough and Salford. The project has generated an significant amount of interest and it is expected to be an exemplar for a new model of collaborative research involving a wide range of engagement between industry and academia. Over the course of the three-year project the research team engaged with hundreds of practitioners from a multiplicity of organisations.

Within the scope of a single paper it is not possible to describe in detail the project, colloquially known as the 'Big Ideas', in its entirety. The purpose of the current paper is to focus on the contribution offered by the work package which focused on system dynamics. Initially, the broad background to the project is described followed by an overview of the adopted research methodology. The origins and nature of system 
dynamics are then described prior to a detailed description of how competitiveness was modelled for a typical contracting firm. Particular emphasis is given to the development of a 'competitiveness index'. For details on other strands of research within the Big Ideas project see: Green et al (2008a), Green et al (2008b), Harty et al (2007), Goodier et al (2007, 2009).

\section{Background}

To understand the background to the 'Big Ideas' we must go back to the Egan report (1998), which proposed a radical transformation of the UK construction sector. Egan identified five key drivers of change: committed leadership, a focus on the customer, integrated processes and teams, a quality driven agenda, and a commitment to people. The Strategic Forum was subsequently formed in 2001 to oversee the industry reform movement. This resulted in a revised set of targets for achieving industry reform by the end of 2007 (Strategic Forum, 2002). More recently the time horizon has been extended through to the 2012. Current emphasis is given to the 2012 Construction Commitments which seek to promote enlightened practices on the back of the construction works relating to the 2012 Olympic Games.

Egan's (1998) initial agenda and the subsequent emphasis on instrumental targets were in no small way directed at overcoming industry failings caused by sector fragmentation. However, the overwhelming tendency was to focus on the 'barriers to change' as if such barriers were static entities. There has been little attempt to understand the way in which the advocated best practice approaches relate to the pre-existing dynamics of industry change.

It must also be recognised that the construction sector has never really existed as a coherent entity and the causes of fragmentation are deeply-rooted (Rabeneck, 2007). Furthermore, since the late-1970s, industry fragmentation has been exacerbated by the vicissitudes of successive policy and procurement initiatives which have acted accumulatively to encourage the growth of self-employment (Harvey, 2003). The demise

of the public sector Direct Labour Organisations (DLOs) also did much to erode the 
industry's traditional training base. These factors combined to reinforce the adopted model of 'structural flexibility' as the key means of achieving competitive advantage (Winch, 1998). The end result is a contracting sector dominated by 'hollowed-out' firms with few direct employees, thereby raising concerns about the industry's absorptive capacity and its ability to innovate (Gann, 2001). The Egan initiative was therefore directed at a sector that was already locked into a 'low road' development path (Best, 1990; Bosch and Philips, 2003) and the isomorphic forces at work were not so easily overcome. Hence it is not surprising that progress in implementing the improvement agenda has subsequently been described as 'slow and patchy'. Certainly there has been little willingness to reinforce the rhetorical exhortations of the Egan Report (Date?) through regulation or institutional reform.

Progress has undoubtedly been made in overcoming the industry's more overt adversarial practices, and the construction sector has made significant progress in embracing new (digital) technologies. But the quest for rationalisation has arguably encouraged a reliance on routine and structured approaches at the expense of imagination, innovation and professionalism (Hughes, 2003). In this respect, the continuous advocacy of key performance indicators (KPIs) is part of the problem rather than part of the solution. Moreover, a review of the annual data shows that performance against most indices has reached a plateau, often with little overall improvement (DBERR, 2008).

Others have alluded to the possibility that the Egan agenda may have served to legitimise trends that were already happening, rather than challenge the basis of existing embedded practices (Green et al, 2008). But most telling of all is the way in which the improvement agenda remains of marginal relevance to the day-to-day challenges faced by the majority of firms in the construction sector. The Big Ideas project therefore set out to engage with the day-to-day realities of those who have felt marginalised by the currently accepted discourse of industry improvement.

But an even more striking observation is that the post-Egan improvement debate has been too focused on improving industry performance as measured by the needs of today; there 
has to date been little attempt to focus on what needs to be done if the sector is to serve the needs of society tomorrow. And here lies a further important message from the Big Ideas project: the challenges of the future will not be the same as the challenges of the present. Climate change, global economic re-structuring, demographic change and an increasing emphasis on social inclusion provide just a few pointers towards future challenges to be faced. Such challenges are entirely beyond the reach of those current best practice ideas which focus almost exclusively on productivity, efficiency and improving collaborative working.

\section{Research methodology}

\section{Overview}

The research sought to address construction sector competitiveness from a systems perspective. Too many previous research projects were seen to focus on narrowly defined issues of productivity to the detriment of broader considerations. The Big Ideas project set out to build on the tradition of socio-technical systems analysis pioneered by the Tavistock Institute (1966). Central to this approach was the recognition that organizations comprise both a technological production system and a social system of the people managing and operating the technology. The Tavistock (1966) report advocated 'collaborative leadership for change' as the model of future action. The themes of

collaboration, learning and a process view were subsequently emphasised by Latham (1994) and Egan (1998), but without the rigour of the underlying socio-technical systems analysis. Adopting a systems perspective on construction sector performance focuses attention onto the inter-connectivity and relationships between different parts of the sector. It further emphasizes the 'emergent' (often undesirable) properties that arise from the way the parts are organized. It is particularly important to understand how the behaviour of individual decision makers is structured by their function within the wider system (Winch, 2002). 
Whilst rooted in the 1960s, systems approaches have developed significantly in recent years. A diversity of techniques are now available that enable both structural and cultural issues to be addressed and modelled (Jackson, 2000; Mingers and Gill, 1997; Mideley, 2000; Rosenhead and Mingers, 2001). The current research sought to follow the principles of a 'multimethodology' research design (Mingers, 2001). In addition to system dynamics (SD), the broader research project was informed by the soft systems methodology (SSM, Checkland (1981). SD is frequently used as part of multimethodology approaches and can be usefully combined with cognitive mapping and SSM (Coyle and Alexander, 1997; Mingers and Rosenhead, 2001).

Appropriate use was also made of a wide range of interpretative research approaches. The methodology in its totality was specifically designed to deal with related aspects of the construction sector: (i) underlying social structures, (ii) differing personal constructs and rationalities, and (iii) underlying causal structures. These interacting influences are seen to be central to the dominant industry recipe of competitiveness, and yet they are rarely taken in account by those who advocate industry improvement. Their explicit recognition guards against the reductionist tendencies of many previous construction sector research projects.

\section{System dynamics}

SD was initially developed by Forrester (1961) to reflect the view that the dynamics of industrial systems result from underlying the structure of flows, delays, information and feedback. Mathematical models of the relations between system components are constructed and the model is run as a computer simulation. Interest in SD has been stimulated by the availability of graphical software and Senge's (1990) popularisation within the context of the learning organisation. In contrast to Forrester's original conceptualisation, the modelling process is now primarily seen as a vehicle for the development of learning and social coordination (de Geus, 1994; Sterman, 2000; Vennix, 1996). SD modelling focuses attention onto complex relationships and creates an environment that enables wide participation by diverse stakeholders. The elements of a system are modelled to interact through mutually causative feedback loops thereby 
providing an enhanced understanding of selected dynamic features of current trends and policies which determine the construction sector's development. Rather than attempt to model the construction sector as a whole, aspects were selected for modelling on the basis of perceived importance and likely impact as identified in the concurrent empirical research. For example, the decline of traditional construction skills in local communities was highlighted by many participants as an issue of concern.

SD modelling has been widely implemented as a means of strategy support. Particular examples include Dangerfield and Roberts' (2000) strategic evaluation of capacity retirements in the UK steel industry where they demonstrated how policies adopted in response to a depressed financial performance only laid the basis for yet further financial tensions at a later point in time. The steel industry study was seen as especially relevant given current concerns regarding the future capacity of the UK construction sector.

Bajracharya et al's (2000) case study of the infrastructure for training activities in the Nepalese construction sector is another example of the use of SD for an issue of strategic importance.

SD modelling can be especially powerful in challenging the mental models of those involved. The active participation of industry representatives has been an essential component of the adopted approach in this research. It should be emphasised that multiple policy insights can be derived from the modelling process itself. The approach focused on simulation runs across a range of policy choices and future scenarios. The SD models were further used in their own right as a scenario generation tool to supplement the futures studies described in Goodier et al (2007, 2009). An additional benefit of the SD modelling process related to the insights into the ways in which dynamic structural relationships may impede or facilitate desired industry change..

Furthermore, 'microworlds' were developed in the form of management flight-simulators (Morecroft, 1984) thereby helping foster learning by senior industrialists and policy makers. A microworld is essentially an interface to the model that enables participants with limited quantitative skills to rehearse policy interventions and ultimately to grasp the 
learning coming from the model. One of the key strengths of participative approaches to SD modelling is the way that it combines research outcomes with an ongoing commitment to dissemination. The preferred software in the Big Ideas project was $\operatorname{VENSIM}{ }^{\circledR}$. This has previously been found to be sufficiently robust to enable the modelling of complex dynamic systems, whilst providing excellent transparency for nonspecialist users.

\section{System dynamics modelling at the firm level}

\section{Multiple models}

Data was sourced from concurrent empirical research into the way in which competitiveness is enacted within regional contracting firms. This provided the necessary information to enable a series of multiple cause-and-effect analyses to be performed using SD. The first stage of the SD modelling process involved the development of influence diagrams from the cognitive maps produced by researchers from the University of Loughborough. A fragment of one of the influence diagrams is included as figure 4. In accordance with the overall philosophy of the proposal, particular attention was given to the broader systemic implications of current trends and policies. In recognition of the complex and multi-perspective nature of construction competitiveness, different SD models were prepared at different levels of aggregation: firm, sector and national. This paper concentrates only on the former: contracting firms acting in competition. .

\section{Competiveness model}

The most significant stream of SD modelling work involved the formulation of a model which reflects a competitive situation and allows performance of an individual constituent entity (a contracting firm in this case) to be evaluated in the light of different policies. To this end a generic contractors' model was formulated. The model incorporated three stylised general contracting firms, A-C, in competition (although any number of competitors could have been used). The methodology allows various resources to be modelled - materials, money, people - but, moreover, also considers the policies 
which govern the management of these resources which, in turn, determine the firm's competitive strength. The model, when run, dynamically traces out the performance of individual variables over a period of time. If a firm is under-performing then its 'competitors' can react and secure a further advantage.

The purpose of this study was to assess policy issues and highlight those which might result in a sustained performance, as opposed to policies which might predicate intermittent crises. The model did not purport to produce a 'forecast' of what might happen to a real-life construction firm, but rather it is an instrument of learning - to suggest how some policies can lead to competitive benefits whilst others are deficient or capable of producing unexpected behaviour. The notional contracting firms are generic although their structure mimics typical firms in the industry and both that and the model's parameters have been determined through interviews with industry executives. Although the firms in this model are generic, it would be perfectly possible to parameterise one of them to equate with a particular real-world contracting firm.

\section{High-level map}

A representation of the overall view of the contractors' model in the form of a high-level map is depicted in Figure 1. It shows that the typical contracting firm must manage human resources, money and materials. Its performance is affected by its competitor's actions but, aside from them, there are other issues which affect a firm's reputation and which in turn have largely been determined by its own actions. These include control of project over-runs, late starts and financial shortfalls. These sort of issues affect a contracting firm's competitive position and thus its ability to win further contracts in the market place. 


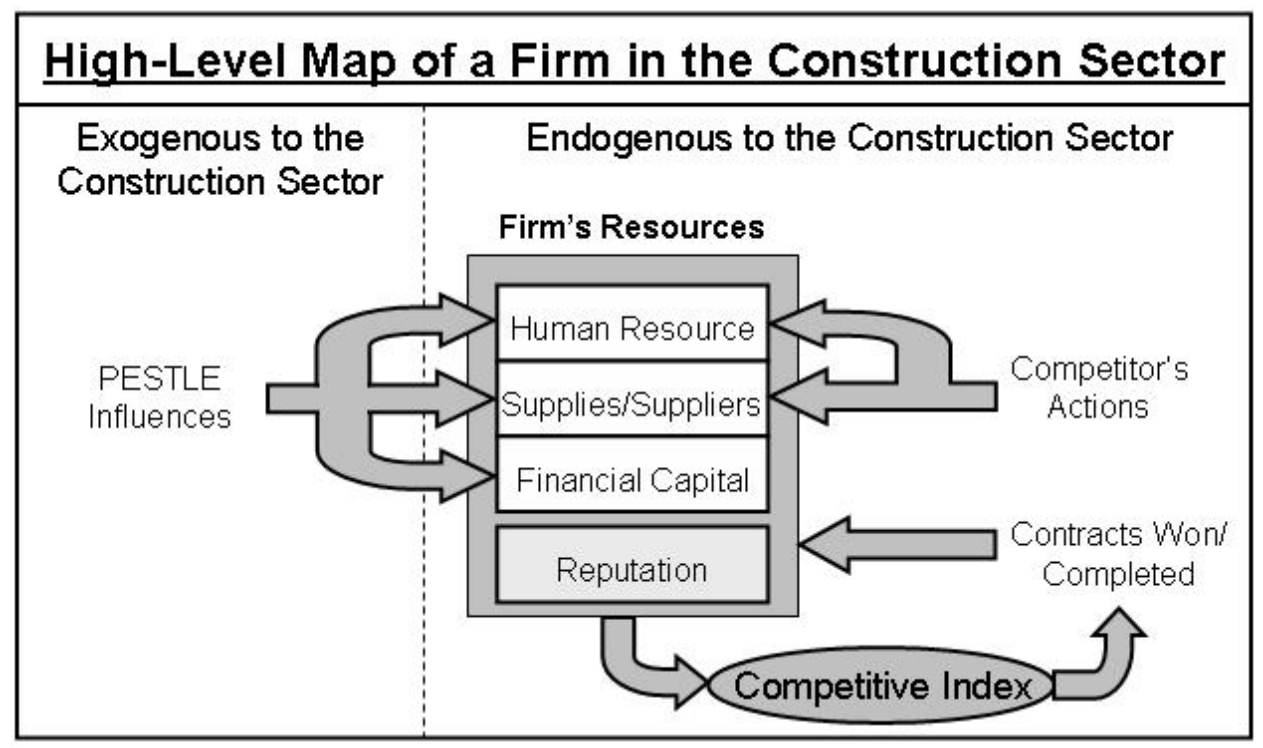

\section{Figure 1: High-level map of a generic firm in the contractors' model}

On top of the internal management issues there are exogenous influences which all the competing contracting firms have to face. These can have an impact on all of the firm's resources and range from Chinese economic development impacting on the world demand for construction steel through to governmental regulatory legislation directly targeted at the industry.

In the SD modelling methodology a high-level map (such as shown in figure 1) represents an overall view of the model to be formulated. The subsequent tasks are to 'drill down' and formulate, in more detail, the various components of the high-level map. Some of these components are expanded upon below, concentrating upon the influences on the competitive index shown in the lower part of figure 1.

The overall structure of figure 1 was determined to be an adequate representation of a contracting firm operating in a competitive market. Its content was underpinned by knowledge uncovered by the other teams in the project as well as the construction industry literature - for example Harvey and Ashworth, (1993). Further, the structure was exposed to practitioners as part of the validation process. 


\section{The Competitive Index}

The factors affecting a contracting firm's reputation are handled in the model by the establishment of a competitive index. This is a means to embrace the range of factors which impact on competitiveness and implicitly recognises that the concept it is a multidimensional one. The references to $\mathrm{Lu}$ (2006) and Sha et al (2008) in respect of the Chinese construction industry reveal that this is not a new idea. But whereas their index formulations are used on ex post construction industry data, ours is embedded in a dynamic model and so is continually being re-computed 'on the fly' as the simulation proceeds.

The design of the competitive index is as depicted in figure 2 for a single contracting firm. The spokes leading to the central ellipse are competitive factors (CF) each of which contribute to the calculation of the overall competitive index (CI) for that firm. The factors are each assigned weights (W). The spoke lengths are variable reflecting the strength of that factor at varying points in time. Lengthening of the spoke length may reflect an improved performance if the competitive factor was, say, revenue and a deteriorating performance if it reflected a late completion time on the contract. These spoke lengths can and do vary as the model simulation proceeds through time. The weights on the other hand will not: they reflect the relative importance of each competitive factor in the given market. This is emphasised by the diameter of the nodes representing the weights at the end of each spoke. 


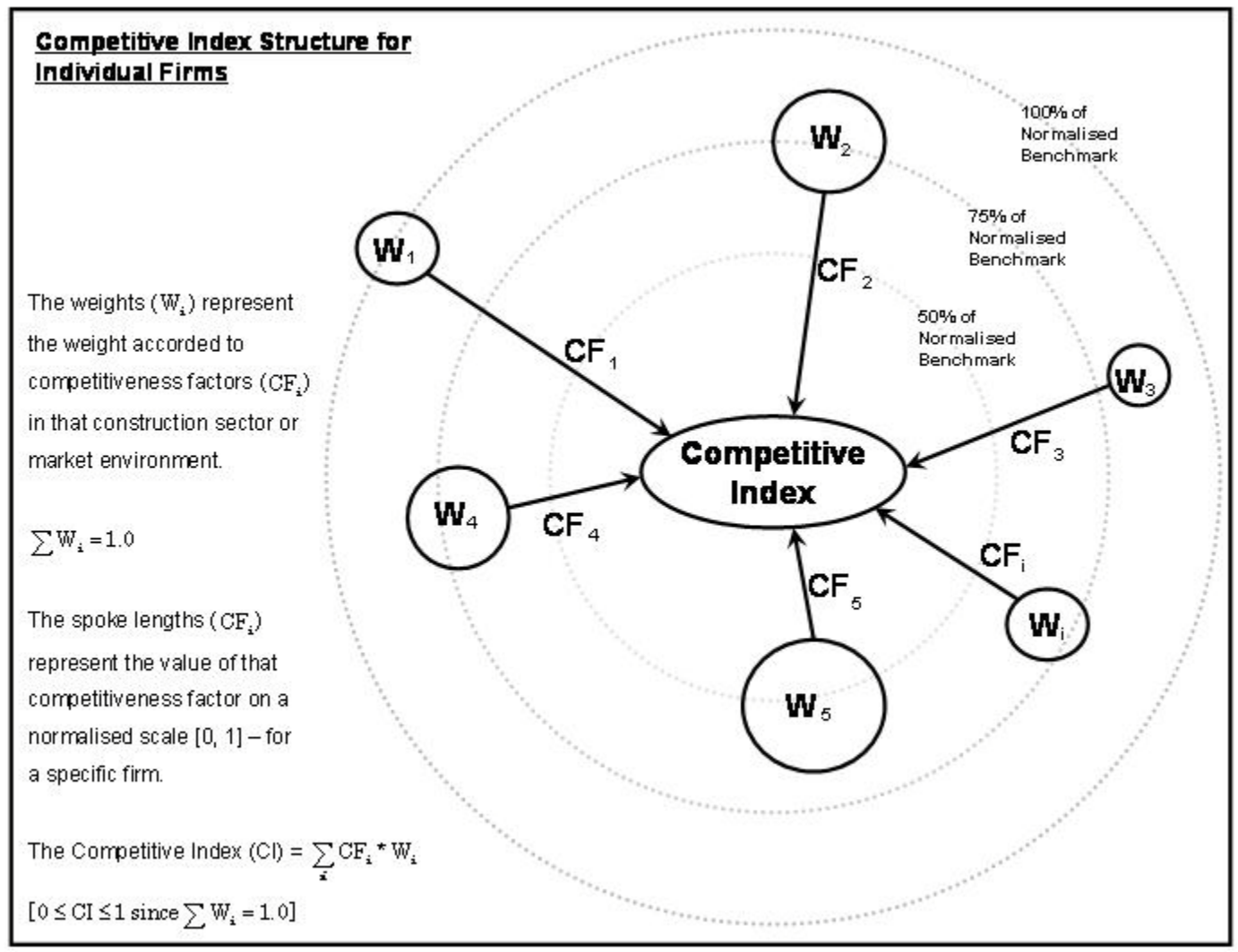

Figure 2 - Diagrammatic representation of the competitive index as used in the model

The mathematics involved is highlighted in figure 2. The weights are constrained to sum to 1.0 and the value of each competitive factor is normalised to a scale of $0-1$. This is achieved by determining the best (largest or smallest as appropriate) of the three competing firm's values for a given CF and awarding this the value of 1.0. The other (two) values are then calculated as pro-rata values against the best value. This is the mechanism used by the World Bank to determine the competitiveness of different nations. It should be noted that this is not the same normalisation process as that adopted by Sha et al (2008). The approach they have adopted ensures that the full range of the scale is used. Thus, under their method, one firm will always score 0 and another 1.0 on any given competitive factor.

On the other hand the method we have adopted allows one to determine how far off the 'best' any given firm is for any given competitive factor. For instance, it can be seen that 
the hypothetical firm depicted scores the best for competitive factor 1 but is only at $75 \%$ of the normalised benchmark for CF's 2 and 4. It performs worst on CF 5 where it is at only $50 \%$ of the normalised benchmark and this performance might prove costly since CF 5 has the largest weight. All of this assumes that, for all CF's, largest is best.

The competitive index (CI) is the weighted sum of the individual weights times the normalised values of each competitive factor. It must result in a value in the range of 0 to 1.0 and is re-computed at every time step in the simulation. A firm will be awarded contracts in proportion to its own CI value over the sum of all firms' CI values. In this way its 'reputation' (figure 1) is fed back into its ability to secure future contracts. It should be understood that this means that if each of the three firms have the same CI (whether that be, say, $0.33,0.5,0.6$ or indeed 1.0 ) they will each receive the same share of the contracts on offer in the market: one-third in this case.

\section{Sectors of the model}

The model has three main sectors: contracts and work-in-progress; finance; and human resources. The first of these is shown in figure 3. Although there are assumed to be three competing firms in this market the diagrammatic representation is common: the differing firms are handled by an array facility in the software employed. The rectangles represent stocks (accumulations) whilst the valve symbols depict management control and thus the policy leverage points. Raising or lowering a flow affects the stock immediately before

and/or after it. Two policy domains which are suggested by a consideration of figure 3 are, firstly, the allocation of contracts and whether to bid aggressively or take a measured view on future undertakings. Another obvious policy consideration surrounds the management of work-in-progress. Under-performance here will result in late contract completion - a major factor determining a contractor's reputation. 


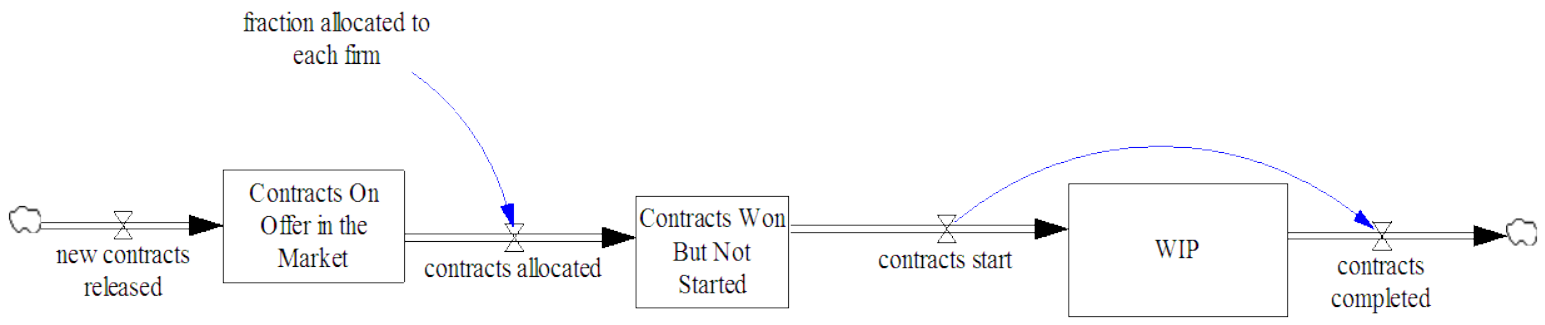

Figure 3 - Flow diagram of the contracts and work-in-progress sector

The fraction of contracts allocated to each firm is, in a raw bidding process, determined by the competitive index as described above. Within the model the influences on this are as illustrated in figure 4. These number four: completion delay; start delay; financial factors; and workforce factors.

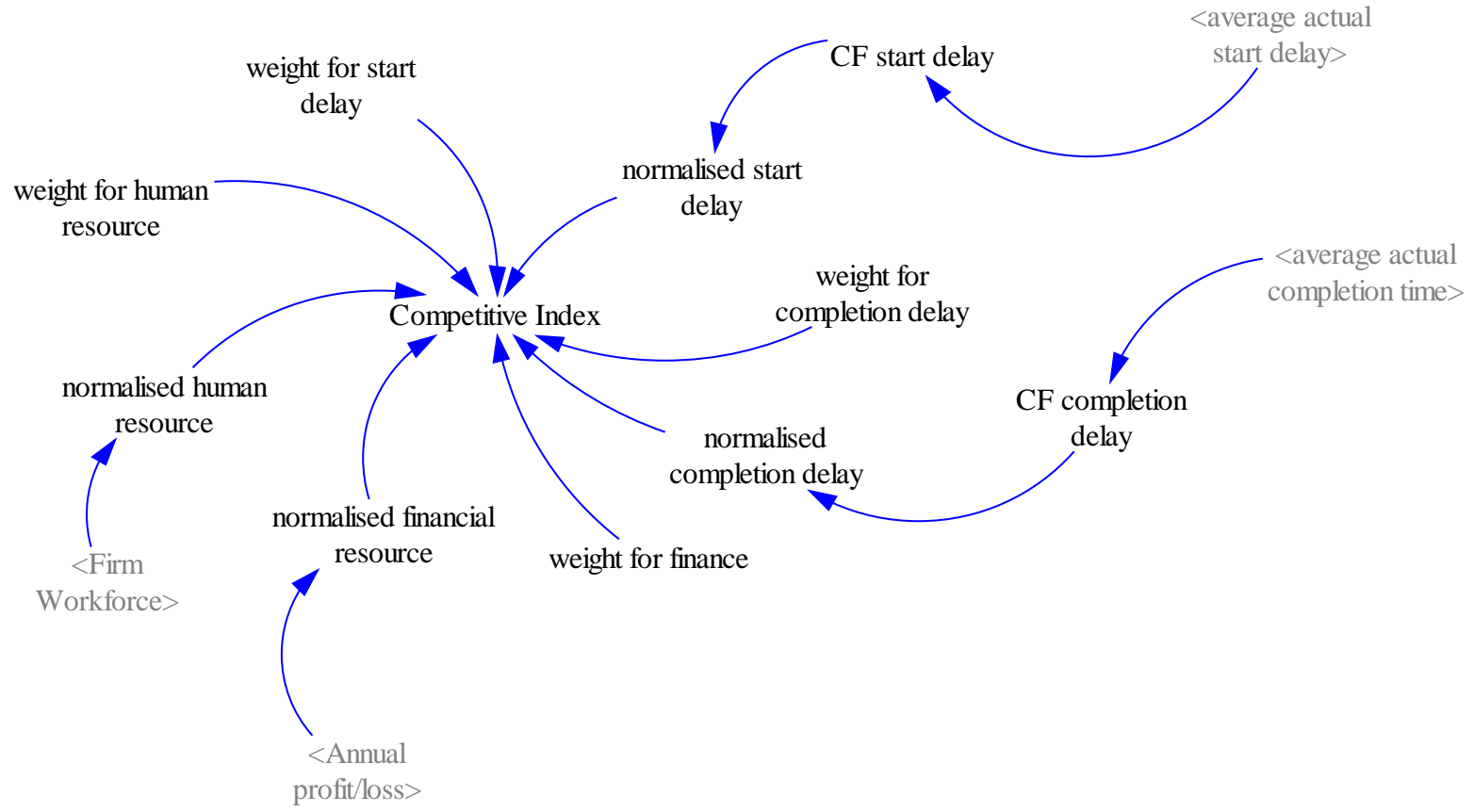

Figure 4 - Influences on the competitive index in the model (Note: variables in angled brackets represent those computed in another model sector) 
The remaining sectors consist of (i) finance and (ii) human resources including those employed directly by the firm and those sub-contracted. The financial sector is simply a revenue-in: costs-out arrangement, although fresh accumulations are made each year to mimic the normal annual financial reporting period. The simulations cover a period of 15 years and the fixed time step is one-eighth of a year. The parameter values currently adopted in the model are listed in Table 1. Obviously these can be changed very easily; indeed a parameter change may form a component of a strategic policy experiment.

\section{Parameter Values}

The following are the main parameter values in the model:

$\begin{array}{ll}\text { Delay in starting contract (normal) } & 1.5 \text { years } \\ \text { Delay in completing contract (normal) } & 1 \text { year } \\ \text { New contracts put on offer } & 50 / \mathrm{yr} \\ \text { Hiring lag } & 1 \text { year } \\ \text { Sub-contracting lag } & 3 \text { months } \\ \text { Average number of employees on site (per contract) } & 50 \text { people } \\ \text { Average revenue per contract p.a. } & £ 4 \text { million } \\ \text { Delay in receiving money } & 3 \text { months } \\ \text { Delay in paying money } & 3 \text { months } \\ \text { Average supply cost per contract p.a. } & £ 0.5 \text { million } \\ \text { Average cost per employee } & £ 20,000 \text { pa }\end{array}$

\section{Table 1: Main parameter values in the model}

\section{Validation of model sectors}

The model described above is formulated on the basis of information gleaned by the other teams involved in the project, together with general knowledge from the construction 
literature. It is, therefore, a generic model. The best way to validate a generic model of this nature is to expose it to the scrutiny of industry experts. Accordingly, a session was held where invited participants were taken through the detail of the model and their comments recorded. The participants were asked three questions:

- Can you identify any fundamental flaws in the model as shown?

- Do you consider there is anything which needs adding to the model?

- Please identify up to 3 issues or causes of concern for which the model might be employed to provide a better understanding

In response, for instance, mention was made of the importance of differentiating between own employees and sub-contracted employees in the human resource sector. Also, the practice of over-trading, when contractors bid even though they don't have the necessary workforce or resources available, was stressed as being something the model needed to deal with.

Had the model been of a specific contracting firm, arguably the model validation process might have been more straightforward. Firm executives would be extremely familiar with the structure and policies of their own firm. Further, there would most likely be some data against which to compare model output and so allow a calibration of the firm's behaviour over time.

\section{Concluding remarks}

It should be stressed that although system dynamics modelling was an important component of the 'Big Ideas' project, it was but one element of an overall methodology which emerged from the synthesis of the different work activities at the three universities. Space prevents detailed discussion of the experiments which have been 
conducted with the SD model described. For more detail on some of the experiments conducted, including the graphical output, see Dangerfield, Quigley and Kearney (2008a and 2008b). For instance, the strength of competitive behaviour (how avidly the firm pursues new contracts) has been shown to be a determinant of profitability. The more aggressive competitive behaviour produces the most severe oscillations in profits. A more measured approach produces oscillations which are much more attenuated (Dangerfield, Quigley and Kearney, 2008b). It is planned to assess the merits of frameworks as an approach to future contracting behaviour.

The over-riding conclusion is that the system dynamics methodology has been shown to be capable of providing a means to assess the forces which shape the sustained competitiveness of construction firms. As such, it takes the assessment of strategic policy analysis in the construction sector onto a higher plane. The need to collect data and make retrospective assessments of competitiveness and strategic performance at the statistical level is not now the only modus operandi available. Models which capture the causative factors operating in the real-world and allow easy experimentation offer a new paradigm for research on construction sector performance.

Whilst the research described has demonstrated the utility of SD modelling in strategic policy evaluation in construction at the proof of concept level, more widespread adoption of it at the level of the individual firm is called for. The team engaged with a small number of individual firms towards the end of the project in an effort to disseminate the overall methodology which emerged from the study. Generic models, such as the one described above, can prove useful in engaging academia but more needs to be done by individual firms to show a willingness to go forward with a model-based methodology for their strategic planning.

However, within the broader context of the Big Ideas project as a whole, the research has demonstrated the possibility of combining quantitative modelling techniques such as system dynamics with qualitative case study research. Data from the case studies can usefully be used to inform the modelling process, and the outcomes from the modelling 
process can initiate discussions which lead to fresh approaches. It has been found to be crucial to possess an in-depth understanding of the challenges faced by contractors prior to engaging in participative modelling workshops.

Contextual understanding is vital. But apart from issues of substance, it is also important to be able to adopt the language that practitioners use to make sense of the challenges that they face. It has been demonstrated that system dynamics modelling can lead to important new insights with direct implications for practice. However, it has also been demonstrated that construction practitioners will only engage with the modelling process if the researchers are able to demonstrate a broad contextual understanding of the challenges faced by contracting firms. The prevailing tendency is to focus on the 'barriers to change' as if such barriers were static entities. There has been little attempt to understand the dynamic inter-relationship between the differing factors which impinge upon construction sector competitiveness. Significant work also remains to be done at the level of construction sector policy in terms of the advocated key performance indicators (KPIs). System dynamics offers the means of evaluating the dynamic interaction between different factors. For example, to date there has been no work to explore the possible feedback effects that may be implicit within 2012 Construction Commitments.

\section{References}

Bajracharya, A., Ogunlana, S. O. and Bach, N. L. (2000) Effective organizational infrastructure for training activities: a case study of the Nepalese construction sector, System Dynamics Review, 16, 91-112.

Best, M. H. (1990) The New Competition: Institutions of Industrial Restructuring, Harvard University Press, Cambridge, MA.

Bosch, G. and Philips, P. (Eds) (2003) Building Chaos: an International comparison of Deregulation in the Construction Industry, Routledge, London. 
Checkland P (1981) Systems Thinking, Systems Practice, Wiley, Chichester.

Coyle, R. and Alexander, M. (1997) Two approaches to qualitative modelling of a nation’s drug trade, System Dynamics Review, 13, 205-22.

Dangerfield, BC and Roberts, CA (2000) A strategic evaluation of capacity retirements in the steel industry, Journal of the Operational Research Society, 51(1), 53-60.

Dangerfield BC, Quigley M and Kearney JR (2008a) A Dynamic Policy Model to Manage Temporal Performance amongst Contracting Firms in a Competitive Situation. Procs of the Transformation through Construction conference, CIB W65/55, Dubai, 2008.

Dangerfield BC, Quigley M and Kearney JR (2008b) A Dynamic Policy Model to Manage Temporal Performance amongst Contracting Firms in a Competitive Situation. Procs of the International System Dynamics Conference, Athens. http://www.systemdynamics.org/conferences/2008/proceed/index.html (Accessed 28 January 2010)

DBERR (2008) Construction Statistics Annual, 2008, Department of Business, Enterprise and Regulatory Reform, London.

Egan, J. (1998) Rethinking Construction: Department of the Environment, Transport and the Regions (DETR), London.

Forrester, J. (1961) Industrial Dynamics, MIT Press, Cambridge, MA. (Now available from Pegasus Communications, Waltham, MA.)

Gann, D. (2001) Putting academic ideas into practice: technological progress and the absorptive capacity of construction organisations, Construction Management and Economics, 19, 321-330.

de Geus, A. P. (1994) Modeling to predict or to learn? In, J.D.W. Morecroft and J.D. 
Sterman (eds) Modeling for Learning Organizations, Productivity Press, Portland, OR.

Goodier, C. I., Soetanto, R., Dainty, A. R. J., Austin, S. A., Price, A. D. and Harty, C. (2007) A competitive future for UK construction?, Construction Information Quarterly, 9(4), 169-174.

Goodier, C. I., Austin, S. A., Soetanto, R. And Dainty, A. R. J.,Causal mapping and scenario building with multiple organisations, accepted for publication in Futures, doi:10.1016/jfutures.2009.11.007.

Green, S. D., Harty, C. F., Elmualim, A. A., Larsen, G. and Kao, C. C. (2008a) On the discourse of construction competitiveness, Building Research \& Information, 36(5), 426435.

Green, S. D., Larsen, G. D. and Kao, C. C. (2008b) Competitive strategy revisited: contested concepts and dynamic capabilities, Construction Management and Economics, 26(1) 63-78.

Harty, C., Goodier, C.I., Soetanto, R., Austin, S.A., Dainty, A.R.J. and Price, A.D.F. (2007) The futures of construction; a critical review of construction futures studies. Construction Management and Economics, 25 (5): 477-493.

Harvey, M. (2003) Privatization, fragmentation and inflexible flexibilization in the UK construction industry, in Building Chaos: A International Comparison of Deregulation in the Construction Industry (Eds. G. Bosch and P. Philips), Routledge, London, pp. 188209.

Harvey RC and Ashworth A (1993) The Construction Industry of Gt Britain, Butterworth-Heinemann, Oxford.

Hughes, W.P. (2003) De-professionalised, automated construction procurement. In 
Foxell, S. (Ed.) The Professionals' Choice: The future of the built environment professions. Building Futures, London.

Jackson, M.C. (2000) Systems Approaches to Management, Klumer Academic, New York.

Latham, M. (1994) Constructing the Team, HMSO, London.

Lu, W.S. (2006) A system for assessing and communicating contractors' competitiveness. Unpublished PhD thesis, Department of Building and Real Estate, Hong Kong Polytechnic.

Midgley, G. A. (2000) Systemic Intervention: Philosophy, Methodology and Practice, Klumer Academic, New York.

Mingers, J. and Gill, A. (1997) Multimethodology: The Theory and Practice of Combining Management Science Methodologies, Wiley, Chichester.

Mingers, J. (2001) Multimethodology - mixing and matching methods, in J. Rosenhead and J. Mingers (eds) Rational Analysis for a Problematic World Revisited, $2^{\text {nd }}$ edn., Wiley, Chichester, pp 289-309.

Morecroft, J.D.W. (1984) System dynamics and microworlds for policymakers, Eur J Opl Res, 35: 301-320.

Senge, P. (1990) The Fifth Discipline: The Art and Practice of the Learning Organisation, Century Books. 
Sha, K., Yang, J., and Song, R. (2008) Competitiveness assessment system for China's construction industry. Building Research and Information, 36(1), 97-109.

Sterman, J. (2000) Business Dynamics: Systems Thinking and Modelling for a Complex World, McGraw-Hill, New York.

Rabeneck, A. (2008) A sketch-plan for construction of built environment theory. Building Research and Information, 36(3), 269-279.

Rosenhead, J. and Mingers, J. (eds.) (2001) Rational Analysis for a Problematic World Revisited, $2^{\text {nd }}$ edn., Wiley, Chichester.

Strategic Forum (2002). Accelerating Change. Rethinking Construction. London.

Tavistock Institute (1966) Interdependence and Uncertainty: A Study of the Building Industry, Tavistock Publications, London.

Vennix, J. A. M. (1996) Group Model Building: Facilitating Team Learning using System Dynamics, Wiley, Chichester.

Winch, G. (1998) The growth of self-employment in British construction, Construction Management and Economics, 16, 531-42.

Winch, G. (2002) Managing Construction Projects, Blackwell, Oxford. 